\title{
Cognitive Performance Deficits and Dysgraphia in Alzheimer's Disease Patients
}

\author{
Emanuela Onofri ${ }^{1}$, Marco Mercuri ${ }^{1}$, MariaLucia Salesi ${ }^{1}$, Max Rapp Ricciardi ${ }^{2}$ and Trevor Archer $^{*}, 2$ \\ ${ }^{I}$ Department of Anatomy, Histology, Legal Medicine and Orthopaedics, Sapienza University of Rome, Italy \\ ${ }^{2}$ Department of Psychology, University of Gothenburg, Gothenburg, Sweden
}

\begin{abstract}
Introduction: Agraphia or dysgraphia, observed often in early AD, encompasses a progressive disorganization and degeneration of the various components of handwriting.

Methods: Deficits in writing ability, dysgraphia, and the relationship with other measures of cognitive decline were studied in a group of 30 patients, originating from the Lazio region, Rome, Italy, presenting a moderate to relatively severe stage of Alzheimer's disease (AD). Extent of dysgraphia and cognitive performance was compared with a matched group of healthy controls selected from the same region.

Results: Several markedly strong relationships between dysgraphia and several measures of cognitive performance in AD patients were observed concomitant with consistent deficits by this patient sample in comparison with the matched group of healthy control subjects were obtained. Additionally, several measures of loss of functional integrity, MMSE, ADL and IADL, were found to be associated with both dysgraphia and impairments in cognitive performance.

Conclusion: The present results are discussed from the notion of affected brain regions underlying functions in cognition, language and motor domains that are disturbed in $\mathrm{AD}$.
\end{abstract}

Keywords: AD, ADL, cognitive tests, correlations, D $\Delta$, deficits, dysgraphia, IADL, MMSE, PQ1.

\section{INTRODUCTION}

According to the World Health Organization (WHO), the number of people affected by dementia was 35.6 millions [1] in the year 2011. This figure is destined to increase at an alarming rate; since the aging of the population $[2,3]$ has an influence both on the incidence and on the prevalence of this syndrome, it has been estimated that by the year 2050 the number of people affected will be 115.4 million [4]. The pathology of dementia is associated with memory loss, loss of orientation, inability to focus attention, loss of speech. The compromised learning capability, ability to calculate, and impaired judgment are often accompanied or preceded by behavioral disturbances, impaired emotional regulation, and lack of motivation [4]. In Western industrial nations, Alzheimer's disease (AD) represents the most common form of dementia [5, 6], approximately $80 \%$ of cases [7], occupying fourth place among the causes of death (after heart disease and circulatory disorders, cancer and cerebral hemorrhage); the secondary forms of dementia, such as vascular dementia, Lewy bodies dementia and the front temporal dementia, appear to be less common [8]. In common, the clinical symptoms presented by AD patients are characterized by memory impairment and at least a cognitive alteration, i.e. aphasia, apraxia, agnosia, or an alteration in executive functions [9], all of which

*Address correspondence to this author at the Department of Psychology, University of Gothenburg, Box 500, SE-40530 Gothenburg, Sweden;

Tel: +46 7864694; Fax: +46 7864628; E-mail: trevor.archer@psy.gu.se complicates the derivation of a differential diagnosis [10]. Even if determined as 'possible' or 'probable' with a percentage of $80 \%$, after tests, blood tests, urine test and spinal cord analysis, or imaging tests such as computed tomography (CT), magnetic resonance imaging (MRI) and through new imaging techniques, diagnosis becomes finally "accepted" only after post-mortem examination of brain tissue $[11,12]$. In this regard, all evidence contributing to loss of function in motor, cognitive and emotional domains ought to be valuable. The neurological damage and cognitive dysfunction, including loss of memory, difficulties of written and oral communication, etc., cause several problems of daily living $[13,14]$, due to which patients are unable to cater their own interests thereby ensuring cumulative deterioration in their quality of life [15].

As early as 1907, Alzheimer [16] had observed in these patients abnormal graphic gestures which indicated that hand writing is not constituted by a unitary process, but that it requires a coordination of linguistic and visual-spatial of the individual $[17,18]$ reflecting brain damage in different associative areas, such as parietal, temporal, occipital and frontal regions [19], subsequently diagnosed in AD patients [20]. Lambert et al. [21] have demonstrated a wide variety of agraphia syndromes, including a far from negligible number of patients with selective damage to one of the central or peripheral components, as well as patients with multiple writing impairments. A positive correlation was observed between the severity of the dementia and spelling/writing measures (lexical and allographic). Agraphia or dysgraphia, observed in early $\mathrm{AD}$ [22], encompasses a progressive 
disorganization and degeneration of the various components of handwriting [23]; these include the complexity of the structure of sentences [24], the diversity and the accuracy of words used [25], punctuation [26], organization [25], the production of grammatically incorrect sentences $[27,28]$, the length of the sentences [27], the amount of written information [28], the morphology of the letters [27] and spelling [29], graphic and spatial layout of letters and their arrangement in texts [18]. Fukui and Lee [30] examined the possibility that agraphia/dysgraphia may be an early sign of degenerative dementia, reporting the concurrent or subsequent emergence of non-fluent aphasia, ideomotor apraxia, executive dysfunction and asymmetric akinesicrigid syndrome; these observations implicate degenerative processes involving the parietal-occipital-temporal regions, basal ganglia and striato-frontal projections. It has been observed that that writing impairment is heterogeneous within the $\mathrm{AD}$ population, but nevertheless, there are certain aspects of the writing process that are more vulnerable than others and may present diagnostic signs [31]. The identification and staging patterns of writing impairment/deficits during different phases of $\mathrm{AD}$ may facilitate the understanding of disease progression and present conditions for the development of relevant interventions.

The purpose of the present study was to examine the relationship between cognitive impairment and the performance of handwritten scripts presented as 'letterwriting' to a close relative by AD patients, as oscillations of the symptoms phase, and in a matched group of healthy controls. It is possible that in graphic expression even by patients diagnosed with moderate to relatively severe $\mathrm{AD}$ there remains some residual capacity for understanding and intention that may be expressed. Thus, a major focus of this study was to reveal, through correlational analyses, the implication of progressive agraphia in degenerative dementia since patients with moderate to relatively severe stage were analyzed. Additionally, comparisons between the $\mathrm{AD}$ patients and healthy controls were analyzed also. Concurrently, the relationship between measures of functioning, Mini-Mental State Examination (MMSE), Activities of Daily Living (ADL) and Instrumental Activities of Daily Living (IADL) with dysgraphia and assessments of cognitive performance was assessed also.

\section{METHODS AND MATERIALS}

\section{Participants}

There were 30 patients who were selected to participate in the study, 12 male and 18 female AD patients who met both the inclusion criteria (see Table 1) and the exclusion criteria, i.e. absence of other neuropsychiatric disorders. The diagnosis was based on normal or nonspecific EEG and lateral, occipital brain atrophy on CT brain with documented progression after serial observations on the cognitive tests and routine blood tests that aimed at excluding the presence of other medical conditions that can justify dementia.

Patients were excluded if they had presented a history of known or suspected cerebrovascular disease, focal neurological signs or on brain imaging, alcohol misuse, head trauma, significant psychiatric history preceding the current diagnosis or other major physical illness. The ages of the participants varied between 73 to 94 years of age. (mean age: 83.06, SD: 6.15). All of the patients were presenting symptoms that indicated a diagnosis of $\mathrm{AD}$ from moderate level to relatively severe (see Table 1). They were diagnosed according to the NINCDS-ADRDA criteria [32] and tothe DSM-IV diagnostic reference. All of these diagnoses were confirmed and verified in 26 patients by resident neurologists at the Department of Neurology at the hospital (Gemelli University Polyclinical-service neuropsychology, Roma and UVA (Alzheimer Evaluation Unit) ASLRMF and UVA (Alzheimer Evaluation Unit) ASLRMD, and in 4 patients from the Department of Neurology and Psychiatry, Sapienza Hospital, Rome) in the Lazio (Rome, Italy) region. The clinical characteristics of the participants in the study are presented in Table 1. The mean length of time spent upon education by the 30 patients was 11.06 years $(\mathrm{SD} \pm 3.6$ years). A considerable amount of time (regular meetings during 3 months) was invested in each of the patients in order to promote a relationship of trust and understanding, as well as to reduce stress factors [6] that may affect patients' mood and attentiveness, or, more seriously, induce dysfunctional behaviors that may be taken for psychiatric incapacity, difficulty to recognize persons, or loss of cognition of time and places through being asked to work with some person whom they did not trust. All the procedures that were adopted according to discussions and meetings with nearest relatives in order to obtain the consent of the patients as well as those relatives (in those cases were the latter were their caregivers/legal representatives) according to the legal practices. The control group of ageand education-matched healthy senior citizens was chosen as individuals that were not in any way influenced by $\mathrm{AD}$ and whom presented the following characteristics: mean age 82.73 years $(\mathrm{SD} \pm 5.7$ years). The mean amount of time spent upon education by the healthy controls was 12.8 years $(\mathrm{SD} \pm 4.04$ years $)$.

AD Diagnosis: All the patients evidenced lower performance in the standard tests of neuropsychological assessment that were administered. The cognitive profiles presented by these patients expressed cognitive impairments that were widespread and related to a severe dementia syndrome of a progressive nature that was linked to a degenerative dementia of the Alzheimer type. On the basis of the neuropsychological tests and clinical observations this group of patients was classified at the moderate to relatively severe stage of $\mathrm{AD}$.

Mini-mental State Examination (MMSE) presents a brief 30-point questionnaire test to screen for cognitive impairment and dementia [33]. It estimates the severity of disorder and follows the course of cognitive changes in an individual over time, thereby allowing effective monitoring of an individual's response to treatment. Table 1 presents the individual scores of each of the patients. It will be noted that these scores range from 11 to 18 which implies that the patients express a moderate level of AD disorder. Healthy control individuals scored at 30 points.

Activities of Daily Living (ADLs) offers an instrument that measures everyday behaviors necessary for normal functioning on a daily basis [34]. Under normal conditions, individuals must invest a certain amount of time taking care 
Table 1. Demographic, neuropsychological and clinical characteristics of each of the AD patients in the present study.

\begin{tabular}{|c|c|c|c|c|c|c|c|c|c|}
\hline Patient No. & Education (yrs) & Age (yrs) & $\operatorname{Sex}(M / F)$ & cognitive deficits & MMSE $^{1}$ & $\mathbf{A D L}^{2}$ & IADL $^{3}$ & $\operatorname{debut}(\mathrm{yrs})^{4}$ & Domicile \\
\hline 1 & 10 & 73 & $\mathrm{~F}$ & aprax, aphas & $16(13,7)$ & 4 & 4 & 3 & relatives \\
\hline 2 & 6 & 93 & $\mathrm{~F}$ & aprax, aphas, agnos & 13 & 4 & 2 & 6 & caregivers \\
\hline 3 & 10 & 91 & $\mathrm{~F}$ & aprax, aphas, agnos & 12 & 4 & 4 & 5 & relatives \\
\hline 4 & 7 & 90 & $\mathrm{~F}$ & aprax, aphas, agnos & 11 & 2 & 2 & 7 & relatives \\
\hline 5 & 15 & 87 & $\mathrm{~F}$ & apraxia, aphasia & $15(15,3)$ & 4 & 4 & 6 & relatives \\
\hline 6 & 8 & 77 & $\mathrm{~F}$ & apraxia, aphasia & $16(15)$ & 5 & 4 & 5 & caregivers \\
\hline 7 & 7 & 78 & $\mathrm{~F}$ & apraxia, aphasia & $14(12,3)$ & 4 & 4 & 4 & relatives \\
\hline 8 & 12 & 79 & $\mathrm{~F}$ & aprax, aphas, agnos & $13(11,3)$ & 4 & 4 & 5 & caregivers \\
\hline 9 & 14 & 79 & $\mathrm{~F}$ & apraxia, aphasia & $15(13,3)$ & 4 & 4 & 4 & caregivers \\
\hline 10 & 8 & 80 & $\mathrm{~F}$ & apraxia, aphasia & $17(16,7)$ & 5 & 4 & 3 & relatives \\
\hline 11 & 14 & 77 & $\mathrm{~F}$ & aprax, aphas, agnos & $14(12,3)$ & 4 & 4 & 4 & relatives \\
\hline 12 & 13 & 77 & $\mathrm{~F}$ & aphasia, apraxia & $17(15,3)$ & 4 & 4 & 3 & caregivers \\
\hline 13 & 12 & 81 & M & apraxia, aphasia & $15(14,7)$ & 4 & 4 & 4 & caregivers \\
\hline 14 & 16 & 85 & M & aprax, aphas, agnos & $12(12,3)$ & 4 & 2 & 5 & relatives \\
\hline 15 & 15 & 83 & M & agnos, aprax & $11(10,1)$ & 4 & 2 & 6 & relatives \\
\hline 16 & 15 & 83 & M & aphasia, apraxia & $14(13,1)$ & 4 & 2 & 5 & caregivers \\
\hline 17 & 8 & 80 & M & apraxia, aphasia, & $17(16,7)$ & 5 & 2 & 3 & relatives \\
\hline 18 & 17 & 80 & M & apraxia, aphasia, & $14(13,1)$ & 4 & 4 & 4 & relatives \\
\hline 19 & 6 & 94 & M & agnosia, apraxia & 16 & 4 & 4 & 2 & relatives \\
\hline 20 & 8 & 93 & M & apraxia, agnosia, aphasia & 14 & 4 & 4 & 5 & caregivers \\
\hline 21 & 10 & 92 & $\mathrm{~F}$ & agnosia, apraxia & 12 & 4 & 4 & 4 & relatives \\
\hline 22 & 7 & 91 & $\mathrm{~F}$ & aphasia, apraxia & 15 & 4 & 4 & 5 & relatives \\
\hline 23 & 18 & 80 & M & aphasia, apraxia & $17(16,1)$ & 4 & 2 & 3 & relatives \\
\hline 24 & 10 & 78 & M & apraxia, & $17(16)$ & 5 & 4 & 4 & relatives \\
\hline 25 & 12 & 77 & M & apraxia, aphasia & $17(16)$ & 4 & 4 & 4 & caregivers \\
\hline 26 & 10 & 76 & $\mathrm{~F}$ & aphasia, apraxia & $16(15)$ & 5 & 4 & 4 & relatives \\
\hline 27 & 13 & 79 & $\mathrm{~F}$ & aphasia, apraxia & $18(16,3)$ & 5 & 4 & 3 & relatives \\
\hline 28 & 16 & 83 & M & agnosia, aphasia & $12(11,1)$ & 2 & 2 & 6 & relatives \\
\hline 29 & 8 & 85 & M & aphasia, apraxia & $12(12,8)$ & 3 & 2 & 5 & caregivers \\
\hline 30 & 7 & 91 & $\mathrm{~F}$ & agnosia, apraxia, aphasia & 11 & 4 & 2 & 6 & caregivers \\
\hline
\end{tabular}

${ }^{1}$ MMSE $=$ mini-mental state examination [33] [normal level score $=30$ points], modified by age and education (numbers in brackets); ${ }^{2}$ ADLs $=$ Activities of Daily living [34] [norma

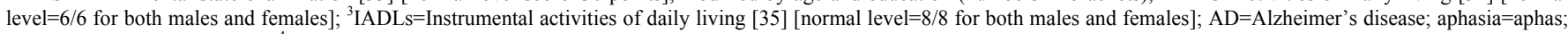
agnos $=$ agnosia; apraxia $=$ aprax; ${ }^{4}$ Debut: numbers of years elapsed since first indication of disorder.

of their personal care and hygiene in order to promote their own health and to a sufficiency of independent initiative and capability.

Instrumental Activities of Daily Living (IADLs) offers an instrument that measures those behaviors that are linked to an independent lifestyle. The instrument has been found to be useful for evaluations of individuals presenting earlystage (or moderate stage) disorders: it has been found applicable for ascertaining both disorder extent and determination of individual capacity for self-care and management [35].
Neurological Data for structural neuro-imaging analysis was obtained from computerized axial tomography (CAT) whereas magnetic resonance imaging (MRI) data were not available. The CAT data were used only for confirmation of diagnosis and were not judged to be of sufficient quality to permit an analysis to combine with the measures of cognitive performance.

\section{Cognitive Performance Assessment: Graphia and Memory Tests}

Testing Material. A tablet (writing-pad) was used for writing text or drawing figures, preferably the vergatina type 
(flimsy type, typing paper or tissue type or absorbent in order to avoid false interpretations of the writings to analyze. A ballpoint pen was used throughout. The patients were invited to sit in a comfortable position.

\section{Procedure}

In order to test the cognitive performance of $\mathrm{AD}$ patients and healthy controls, as well as their spatial and time orientation and their residual capacity, a standard collection of 14 simple questions were presented to the patients and controls. The questions were derived and modified from the MMSE 1 and 2 items to cover the temporal and spatial orientation. These questions were designed and presented in a form that could be utilized by any General Practitioner (GP) in order to document the level of cognitive functioning of each patient. For each correct answer one point was attributed in proportion to the difficulty of the question (see Table 2). The total sum from each test session was represented by PQ: the initial session result designated PQ1. Following this, each patient was then invited to write a letter to a close relative. On consecutive days of testing patients were invited to write to either the same relative or another one. Using a chronometer to establish length of writing-time (min.), the letter-writing task was interrupted when it seemed that the text produced by the patient was substantially (pathologically) confused, both with regard to spatial disorientation as well as for a sudden lack of readability, disjointedness and incompleteness in meaning (see Fig. 1). After this, the number of minutes (min) that had been reached for each single patient was registered. For Patient $\mathrm{X}$ (see above) the whole procedure involving the letter-writing graphia task was interrupted after 10 minutes since the patient continued to write, but in an incomprehensible manner. After having terminated the writing session, the
Table 2. Assessment test of cognitive functions consisting of 14 items (see below), modified version of the Folstein MMSE (1975), adapted specially for patients presenting severe AD. An imaginary example of a patient is provided below.

\begin{tabular}{|l|c|}
\hline Personal Details & Score \\
\hline \hline 1. What is your name? & $0-3$ \\
\hline 2. When were you born? & $0-2$ \\
\hline 3. Who am I? & $0-2$ \\
\hline Temporal Orientation & Score \\
\hline \hline 9. What year is it? & $0-1$ \\
\hline 10. What season are we in? & $0-1$ \\
\hline 11. What month is it? & $0-1$ \\
\hline 12. What is the date today? & $0-1$ \\
\hline 13. What day of the week is today? & $0-1$ \\
\hline 14. Is it day or night? & $0-2$ \\
\hline Spatial Orientation & Score \\
\hline \hline 4. What country are we in? & $0-1$ \\
\hline 5. In which Italian region are we in? & $0-1$ \\
\hline 6. In which city are we in? & $0-1$ \\
\hline 7. What floor are we at? & $0-1$ \\
\hline 8. Where are you & $0-2$ \\
\hline Total score, PQ = 20 points. & \\
\hline
\end{tabular}

questionnaire was presented again to the patients with the scores thus provided constituting PQ2.
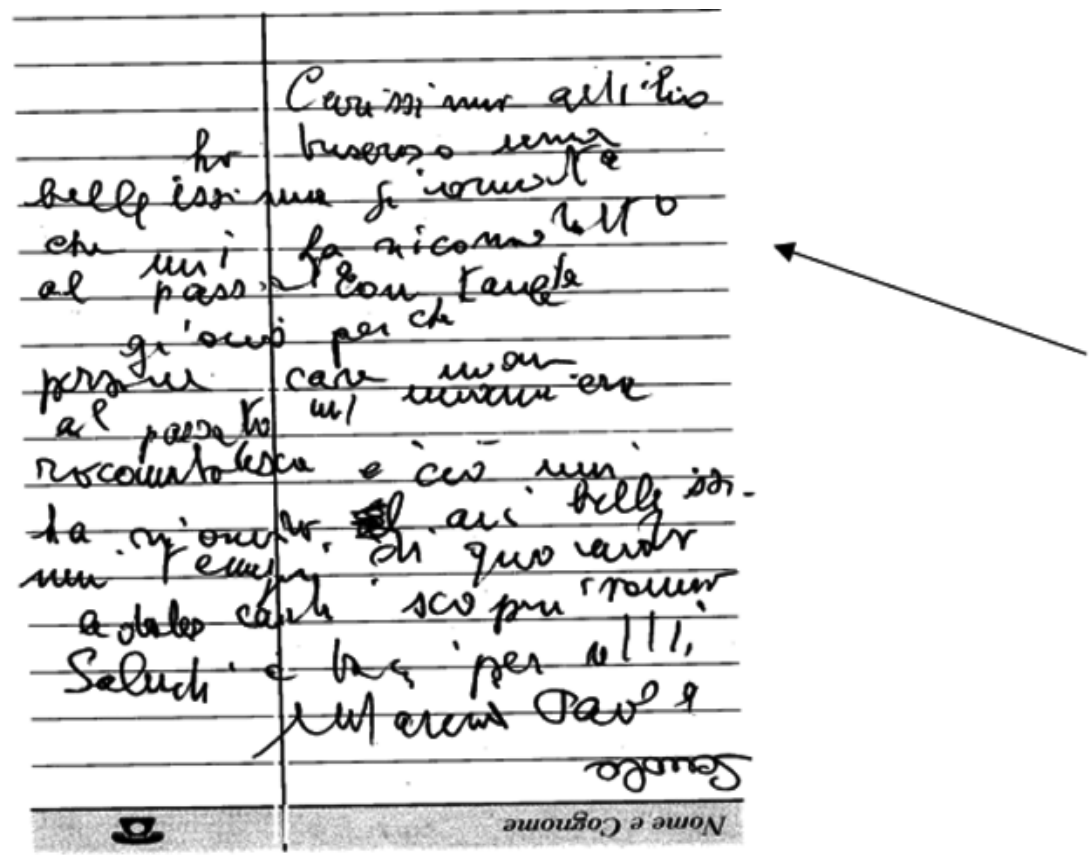

Patient $X$ performance:

PQ1 score $=14$, began writing; Stopwatch turned off after 10 min. due to incoherence; PQ2 test score $=7$.

Fig. (1). Depicts the performance of Patient X during PQ1 followed by the letter-writing test followed by PQ2. The quality of handwriting, coherence and comprehension is taken into account before deciding to terminate the writing session. 
As a test for patients presenting dementia this set-up appears to offer a good indicator of the fragility of cognitive function. The list of 14 questions presented in PQ1 was presented again in a repeated procedure that was designated PQ2. The difference between these two measures (PQ1-PQ2) was designated D $\Delta$. These procedures for testing: 14-item test - graphia test - 14item test were presented in an identical manner every second over 10 days (Days 1, 3, 5, 7, 9, 11, 13, 15, 17, and 19) at the same hour-of-day on test days in order to hold constant testing procedures over daily curriculum and any clinical interventions that the patients may be subject to.

The patients responded to questions before personal details and after to questions spatial orientation and after to questions regarding temporal orientation.

\section{Statistical Analysis}

The results consisting of PQ1 and PQ2 scores, min spent writing and D $\Delta$ (see above) was calculated as means and standard deviations of the AD patient group and the healthy control group over consecutive days of testing. Student's ttests were used to test for pairwise differences for each of the parameters. Pearson's correlation coefficient was used to assess the relationship between writing-time and PQ1 and writing-time and D $\Delta$ over patients and test days.

\section{RESULTS}

\section{AD Patients: Cognitive Performance Over PQ1 and PQ2}

The cognitive performance of the AD patients deteriorated from PQ1 to PQ2 (see Table 3) with t-values reaching significance levels over all 10 days of testing.

\section{Correlation Coefficients: PQ1 Versus Writing-Time and Writing-Time Versus $\mathrm{D} \Delta$}

The correlation coefficients of both the PQ1 performance and writing-time relationship and the writing-time and D $\Delta$ relationship were all positive and highly significant (see Table 3).
There were highly significant, positive correlations between the $1^{\text {st }}, \mathrm{PQ} 1$, test and extent writing ability, graphia, and the latter with cognitive performance deterioration, D $\Delta$, over test days summated over all 30 patients. Fig. (2) presents the correlation analysis (coefficient and slope) between PQ1 and writing-time (top) and writing-time and $\mathrm{D} \Delta$ over all 10 days of testing.

Concurrently, there were highly significant, positive correlations between the $1^{\text {st }}$, PQ1, test and extent of writing ability, graphia, and the latter with cognitive performance deterioration, D $\Delta$, over 30 patients summated over all 10 test days. Fig. (3) presents the correlation analysis (coefficient and slope) between PQ1 and writing-time (top) and writingtime and $\mathrm{D} \Delta$ over all 30 patients.

\section{Correlation Analyses Between Functional Measures}

Product moment correlations between the functional estimations of $\mathrm{AD}, \mathrm{ADL}, \mathrm{IADL}$ and $\mathrm{MMSE}$, and the neuropsychological assessments of cognitive performance, PQ1, D $\Delta$ and PQ2, were carried out on the data obtained from the $30 \mathrm{AD}$ patients. It was observed that (i) ADL, IADL and MMSE all correlated significantly with PQ1, albeit at different levels of significance, (ii) IADL and MMSE correlated significantly with $\mathrm{D} \Delta$, (iii) $\mathrm{ADL}$ and MMSE correlated significantly with PQ2, and (iv) ADL and IADL correlated significantly with MMSE.

\section{Comparison AD Patients with Healthy Controls}

There was a marked impairment in the $\mathrm{AD}$ patients and the healthy controls for the expression of extent writing ability, graphia, and the extent of cognitive performance deterioration, $\mathrm{D} \Delta$. Table 5 ( $\mathrm{A}$ and $\mathrm{B}$ ) presents the means $\pm \mathrm{SD}$ as well as t-values over all 10 days of testing.

The extent of dysgraphia by the AD patients was found to be quite advanced in comparison with the healthy controls (see Fig. 4).

Concurrently, the extent of cognitive performance deterioration, $\mathrm{D} \Delta$, from the $1^{\text {st }}$ to the $2^{\text {nd }}$ test, was found to be

Table 3. T-test values between PQ1-PQ2 scores (means \pm SD), and Pearson product moment correlational analyses between (i) PQ1 and writing-time (min), (ii) writing-time (min) and $\mathrm{D} \Delta$ over 10 days of testing (Days 1, 3, 5, 7, 9, 11, 13, 15, 17 and 19).

\begin{tabular}{|c|c|c|c|c|c|}
\hline Test Days & PQ1 & PQ2 & t-values & R (i) & R (ii) \\
\hline 1 & $11.9 \pm 4.8$ & $4.0 \pm 1.9$ & $8,25^{*}$ & $0.802 *$ & $0.905 *$ \\
\hline 5 & $9.9 \pm 5.1$ & $4.8 \pm 3.0$ & $4,71 *$ & $0.603^{\circ}$ & 0.680 * \\
\hline 7 & $9.5 \pm 4.6$ & $5.2 \pm 2.6$ & $4,39 *$ & $0.644^{\circ}$ & $0.755^{*}$ \\
\hline 11 & $8.9 \pm 4.4$ & $5.0 \pm 2.8$ & $4,04 *$ & $0.556^{\mathbf{\Lambda}}$ & $0.646^{\circ}$ \\
\hline 13 & $9.3 \pm 4.3$ & $5.5 \pm 2.7$ & $4,08 *$ & $0.688^{*}$ & $0.542^{\wedge}$ \\
\hline 15 & $8.9 \pm 4.4$ & $5.1 \pm 2.9$ & $3,93 *$ & $0.498^{\bullet}$ & $0.643^{\circ}$ \\
\hline 17 & $9.5 \pm 4.0$ & $5.4 \pm 3.1$ & $4,42 *$ & $0.767^{*}$ & $0.547^{\wedge}$ \\
\hline
\end{tabular}



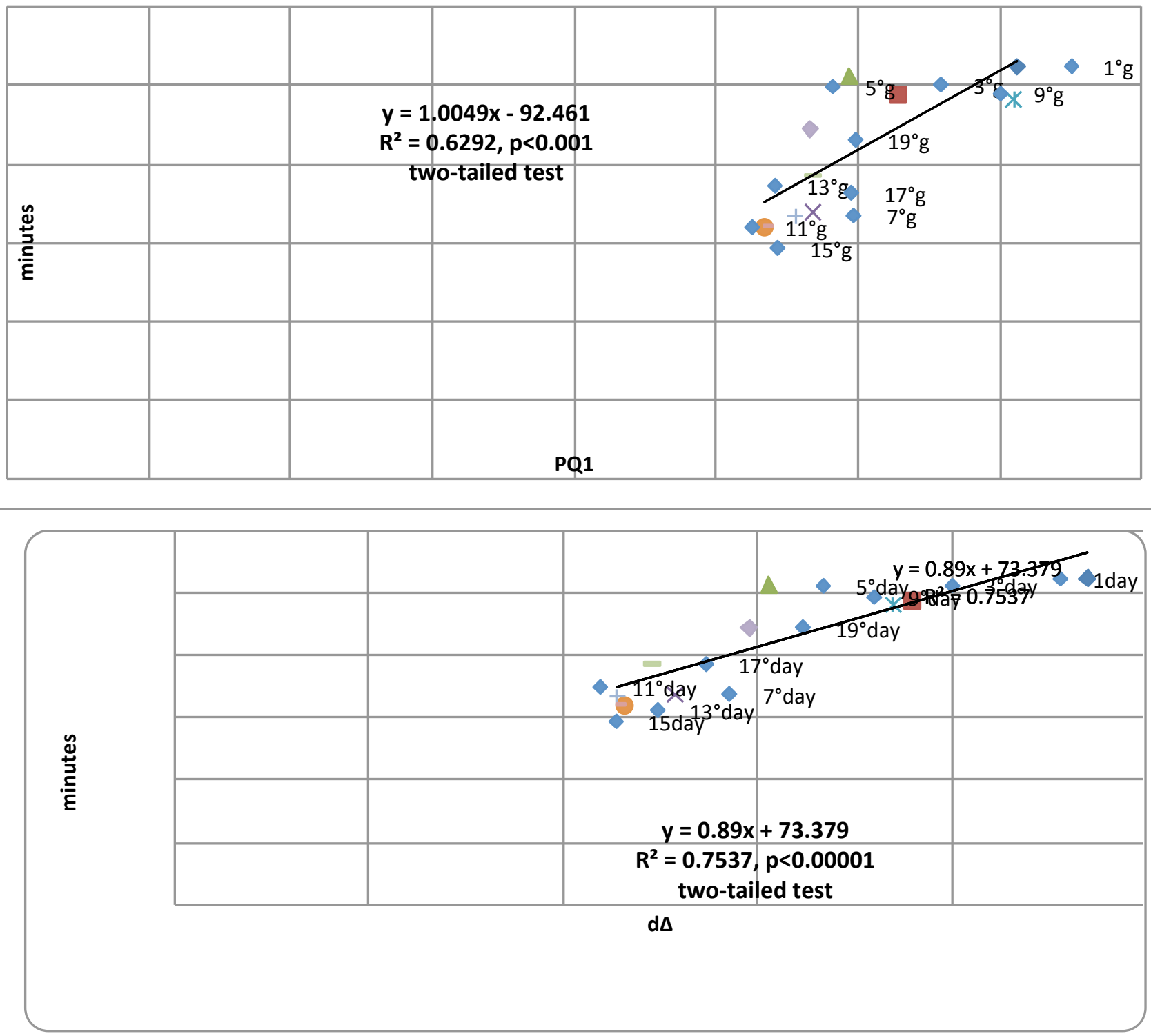

Fig. (2). Top panel. Pearson product moment correlational analyses between PQ1 and writing-time (min) over all 10 days of testing (Days 1, $3,5,7,9,11,13,15,17$ and 19) summated over all 30 patients, Pearson $r=0.793(\mathrm{df}=30), \mathrm{p}<0.000001$. Bottom panel. Pearson product moment correlational analyses between writing-time (min) and $\mathrm{d} \Delta$ over 10 days of testing (Days 1, 3, 5, 7, 9, 11, 13, 15, 17 and 19) summated over all 30 patients, Pearson $\mathrm{r}=0.868(\mathrm{df}=30), \mathrm{p}<0.0000001$, two-tailed tests.

markedly advanced in comparison with the healthy controls (see Fig. 5).

\section{DISCUSSION}

The present study examined the relationships between initial cognitive performance (PQ1), the deterioration in cognitive performance following a letter-writing task (PQ1$\mathrm{PQ} 2=\mathrm{D} \Delta$ ) and dysgraphia in a group of $\mathrm{AD}$ patients presenting a moderate to relatively severe stage of disorder, and comparisons with a matched group of healthy controls. The results may be summarized as follows:

Both the correlations between PQ1 and PQ2 over all the test days and the deterioration of performance from PQ1 to PQ2 over all test days were markedly significant, implying that the cognitive performances over the different measures were linkedstrongly. (ii) The relationships between initial cognitive performance (PQ1) and extent and dysgraphia over both patients and test days were markedly strong. (iii) The relationships between dysgraphia and cognitive deterioration (D $\Delta)$ were also markedly strong. (iv) In comparison with the matched healthy controls, the $\mathrm{AD}$ patients demonstrated deficits in initial cognitive performance (PQ1), the extent to which dysgraphia was expressed and the extent of deterioration due to the insertion of the writing (graphia) test; the extent of deterioration due to the insertion of the writing (graphia) test extremely marked (see Fig. 5). (v) ADL, IADL and MMSE correlated significantly with PQ1, whereas IADL and MMSE correlated significantly with D $\Delta$, ADL and MMSE correlated significantly with PQ2, and ADL and IADL correlated significantly with MMSE (see 

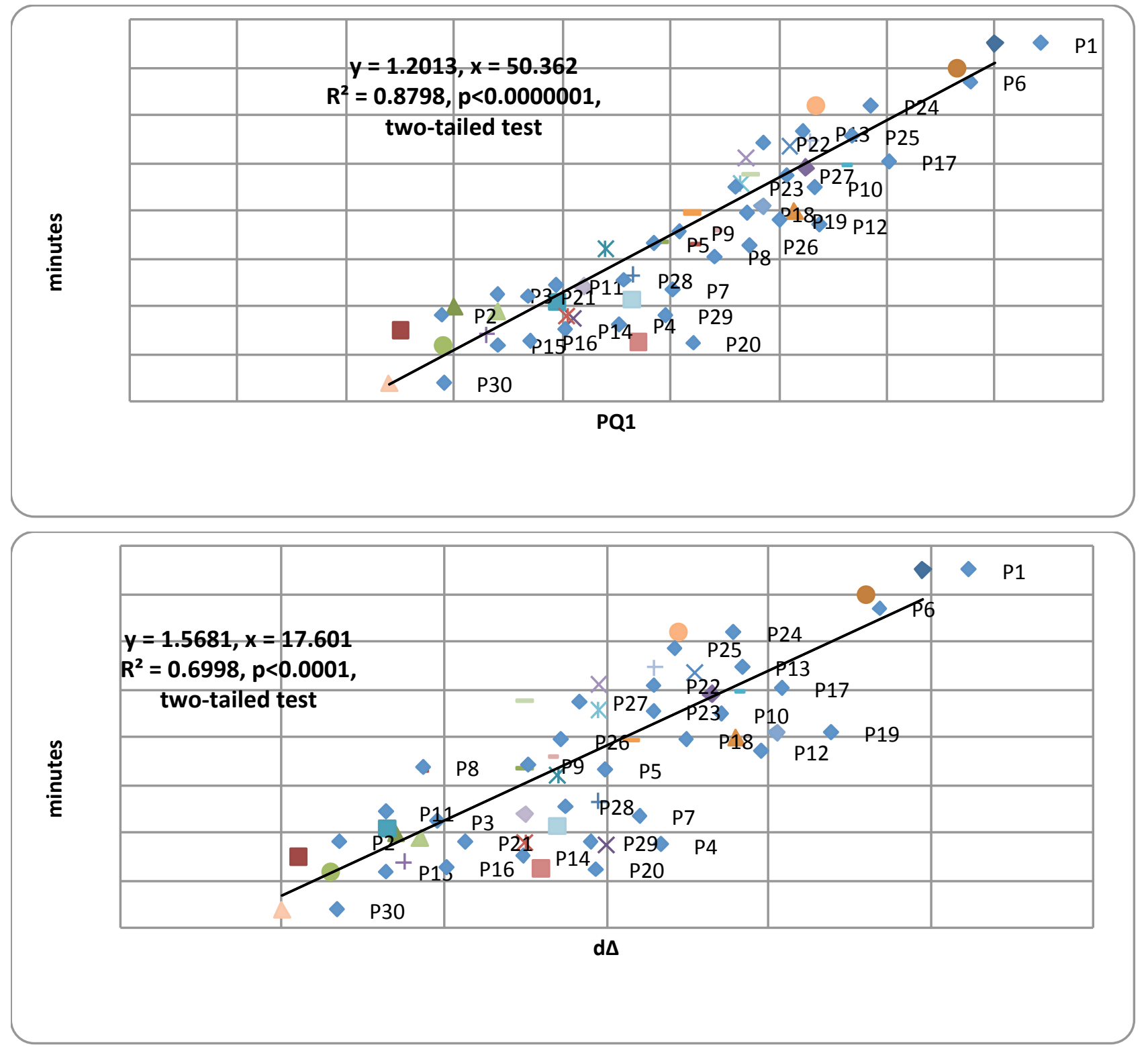

Fig. (3). Top panel. Pearson product moment correlational analyses between PQ1 and time writing (min) over all 30 AD patients summated over all 10 days of testing, Pearson $\mathrm{r}=0.938(\mathrm{df}=12), \mathrm{p}<0.000001$. Bottom panel. Pearson product moment correlational analyses between time writing (min) and $\mathrm{d} \Delta$ over all $30 \mathrm{AD}$ patients summated over all 10 days of testing, Pearson $\mathrm{r}=0.829(\mathrm{df}=12)$, $\mathrm{p}<0.0000001$, two-tailed tests.

Table 4. Pearson product moment correlations between the functional measures, ADL, IADL and MMSE, and the assessments of cognitive performance, $\mathrm{PQ1}, \mathrm{D} \Delta$ and $\mathrm{PQ2}$, in the 30 patients.

\begin{tabular}{|c|c|c|c|c|c|}
\hline & PQ1 & D $\Delta$ & PQ2 & MMSE & Writing-Time \\
\hline \hline ADL & $0.394^{*}$ & $0.223 \mathrm{~ns}$ & $0.512^{* *}$ & $0.611^{* * *}$ & $0.457^{* *}$ \\
\hline IADL & $0.471^{* *}$ & $0.368^{*}$ & $0.124 \mathrm{~ns}$ & $0.378^{*}$ & $0.489^{* *}$ \\
\hline MMSE & $0.711^{* * *}$ & $0.650^{* * *}$ & $0.649 * * *$ & $0.708^{* * *}$ \\
\hline D $\Delta$ & & & & & $0.850^{* * * *}$ \\
\hline
\end{tabular}

ADLs $=$ activities of daily life; IADLs $=$ instrumental activities of daily life; MMSE $=$ mini-mental state examination.

${ }^{*} \mathrm{p}<0.05, * * \mathrm{p}<0.01, * * * \mathrm{p}<0.0005, * * * * \mathrm{p}<0.000001$, two-tailed tests.

Table 4); furthermore, writing-time performances correlated significantly with ADL, IADL, MMSE and D $\Delta$. In particular, the association between writing-time (or expression of dysgraphia) and $\mathrm{D} \Delta$, the deterioration from the $1^{\text {st }}$ cognitive test (PQ1) to the $2^{\text {nd }}(\mathrm{PQ} 2)$, was markedly significant $\left(\mathrm{R}^{2}=0.850\right)$. 
Table 5. Pairwise differences (Student's t-test) between AD patients and controls for (i)4A: writing-time (min), (ii)4B: d $\Delta$, over 10 days of testing (Days 1, 3, 5, 7, 9, 11, 13, 15, 17 and 19).

\begin{tabular}{|c|c|c|c|c|c|c|c|c|c|c|}
\hline A & Day 1 & Day 3 & Day 5 & Day 7 & Day 9 & Day 11 & Day 13 & Day 15 & Day 17 & Day 19 \\
\hline t-values: & $8.80 *$ & $12.32 *$ & $8.47 *$ & $10.49 *$ & $14.49^{*}$ & $12.87^{*}$ & $13.99 *$ & $12.41^{*}$ & $9.00 *$ & $9.00 *$ \\
\hline \multicolumn{11}{|l|}{ AD } \\
\hline Mean & 8.73 & 8.13 & 8.53 & 5.63 & 8.03 & 5.33 & 5.57 & 5.37 & 6.43 & 7.40 \\
\hline SD & 6.65 & 4.90 & 7.10 & 5.35 & 5.97 & 5.23 & 5.84 & 5.60 & 5.49 & 7.39 \\
\hline \multicolumn{11}{|l|}{ Control } \\
\hline Mean & 19.60 & 19.53 & 19.63 & 19.70 & 19.63 & 19.60 & 19.57 & 19.80 & 19.33 & 19.70 \\
\hline SD & 1.25 & 1.28 & 1.00 & 1.15 & 1.00 & 1.30 & 1.17 & 0.76 & 1.52 & 1.15 \\
\hline B & Day 1 & Day 3 & Day 5 & Day 7 & Day 9 & Day 11 & Day 13 & Day 15 & Day 17 & Day 19 \\
\hline t-values: & $8.68^{*}$ & $11.20^{*}$ & $6.90^{*}$ & $7.14^{*}$ & $12.06^{*}$ & $7.65^{*}$ & $6.50^{*}$ & $7.02 *$ & $7.73^{*}$ & $9.00 *$ \\
\hline \multicolumn{11}{|l|}{ AD } \\
\hline Mean & 7.83 & 6.33 & 5.10 & 4.30 & 6.17 & 3.87 & 5.57 & 3.80 & 4.10 & 4.93 \\
\hline SD & 4.85 & 3.03 & 3.95 & 3.19 & 2.72 & 2.62 & 5.84 & 2.86 & 2.71 & 2.89 \\
\hline \multicolumn{11}{|l|}{ Control } \\
\hline Mean & 0.10 & 0.10 & 0.10 & 0.07 & 0.13 & 0.13 & 0.10 & 0.10 & 0.20 & 0.13 \\
\hline SD & 0.55 & 0.31 & 0.40 & 0.64 & 0.35 & 0.51 & 0.40 & 0.40 & 0.55 & 0.43 \\
\hline
\end{tabular}

*versus control group, Student's t-test $(\mathrm{df}=1,58), \mathrm{p}<0.0001$.

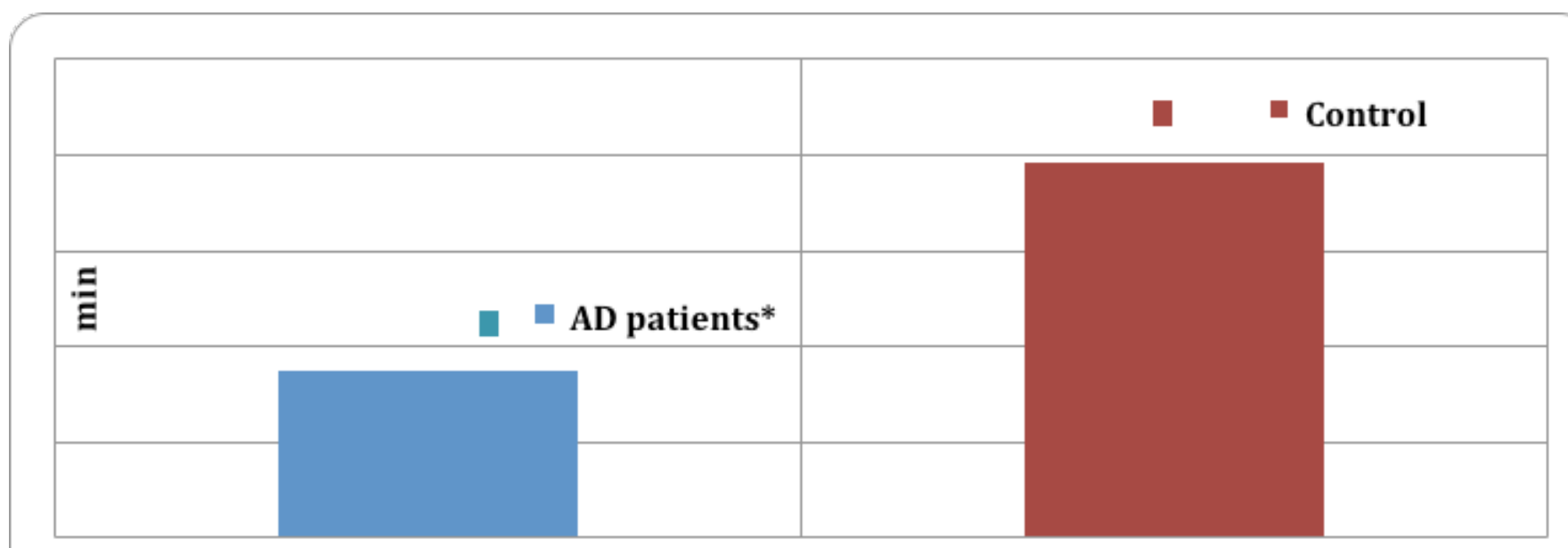

*versus Control group, Student's t-test, $\mathrm{t}(1,598)=35.62, \mathrm{p}<0.0001$.

Fig. (4). The amount of time spent writing (min) by AD patients and healthy controls expressed as means \pm SD in the graphia test, summated over all 12 days of testing.

Dysgraphia occurs during both the earlier as well as the later stages during the clinical course of $\mathrm{AD}[36-38]$ and is associated with attentional, motor and memory deficits that develop during disorder progression [39]. It has been suggested to be a more sensitive indication of language deficits in AD than anomia [22]. Yoon et al. [40] have observed that a sample of 35 patients presenting early onset $\mathrm{AD}$, with a severe degree of hypometabolism in the parietal brain region, exhibited not only linguistic errors but also visuoconstructional manifestations (derived from Hangul scripts) of dysgraphia that were associated with cognitive impairments in multiple domains. In a sample of $75 \mathrm{AD}$ patients and 20 healthy controls that were set Hangul writing tasks, it was found that the writing performance of the AD group was significantly defective with a profusion of different types of errors emerging with disorder progression [41]. PET imaging of glucose metabolism indicated that the hypometabolism in the right occipitotemporal lobe and left 


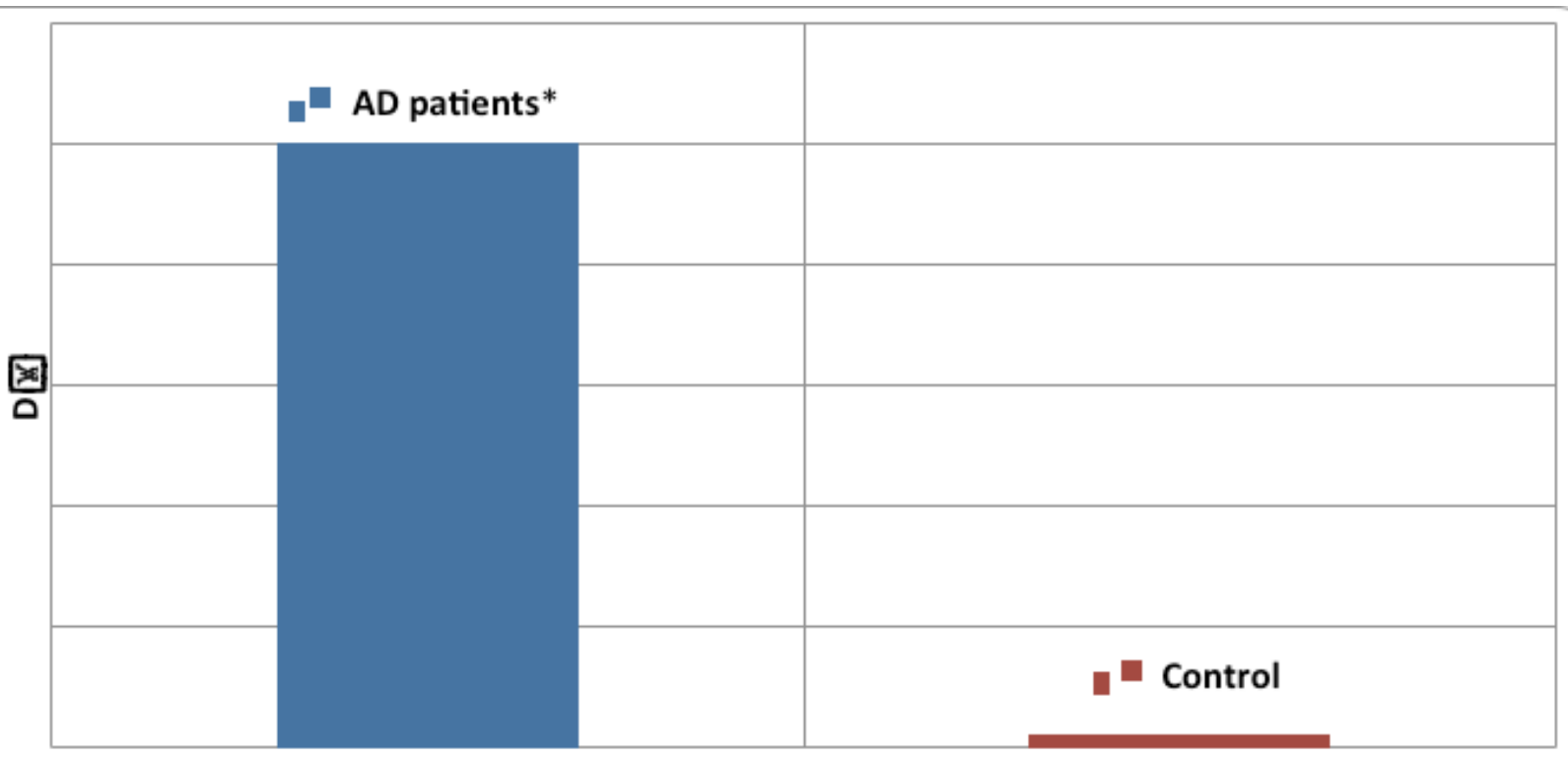

Fig. (5). The difference (D $\Delta$ ) between cognitive performance in PQ1 and PQ2 by AD patients and healthy controls expressed as D $\Delta$ means \pm $\mathrm{SD}$, summated over all 10 days of testing. *versus Control group, Student's t-test, $\mathrm{t}(1,598)=24.35, \mathrm{p}<0.0001$.

temperoparietal lobe was linked to Hangul writing impairment [41], in accordance with lesioning studies of dysgraphia [42]. In a sample of 52 Japanese patients presenting mild AD and 22 healthy controls, writing ability composed of Kana writing-to-dictation and copying Kanji or dictational Kanji, and regional cerebral blood flow using SPECT were studied [43]. They observed that while Kana writing-to-dictation and copying Kanji were preserved in these AD patients, writing to dictated Kanji words was impaired. The impaired writing of dictated Kanji words was associated with dysfunctional cortical activity predominantly in the left frontal, parietal and temporal brain regions [43] consistent with other Japanese dysgraphia studies [44-46]. The present observations of dysgraphia associated with deficits in semantic memory that were exacerbated acutely by the writing task appear to fit current notions pertaining to the progressive performance impairments of AD patients within language and cognition domains from a staging perspective [47, 48].

The possible relationships between dysgraphia and the motor functioning domain in $\mathrm{AD}$ has provided novel insights of the cognitive nature of disorder [21] through which mild to moderate stage AD patients $(n=59)$ and healthy elderly controls were tested over an extensive assessment of both the central and peripheral components of writing; the former performed less effectively than controls over a broad spectrum of writing measures. Although a predominantly lexical disorder was observed, there were multiple indications of associated disorders located at different stages in the writing/spelling system (e.g. phonological route, graphemic buffer, allographic store, graphic motor patterns). The authors concluded that there exist heterogeneous profiles of dysgraphia with primary signs of writing impairment in AD originating from changes at different points in the brain networks that subservewriting and spelling performance [21]. In this regard, the possibility of related motor deficits in dysgraphia ought to be considered since there is evidence for altered parietal-motor connections in $\mathrm{AD}$ [49]. It has been found too that sensory-motor plasticity is impaired in the motor cortex (see above parietal cortex glucose hypometabolism) of AD at an early stage of the disease [50]. Furthermore, clear differences between AD patients and healthy control individuals have been found for visuomotor task measures demonstrating large effect size deficits by AD patients especially with visuomotor task progression through its varying conditions [51]. Sitek et al. [52] have observed dysgraphia, primarily dysexecutive agraphia, in patients with frontotemporal dementia and parkinsonism linked to chromosome 17 (FTDP-17). Patients presenting 'dysexecutive' agraphia show not only difficulties in maintaining the effort inherent to writing but appear to lack the ability to organize their thoughts for expression in the written text. They seem to be lacking in the complicated functions underlying writing that encompass narrative coherence, planning, selective attention, etc, that are disturbed in executive function impairments.

The relationship between MMSE and dysgraphia in AD patients has been established [53, 54], although there remains a paucity of studies examining the associations involving ADL and IADL with dysgraphia. In the present study the expressions of dysgraphia (writing-time) as well as the expressions of cognitive deficits were related strongly to the assessments of functional impairment (MMSE, ADL and IADL). The question arises as to whether the functional deficits expressed by ADL, IADL and MMSE may have contributed to the cognitive performance deficits shown by PQ1, D $\Delta$, PQ2 and writing-time. Choi et al. [55] observed that the expression of extrapyramidal signs in AD patients, non-recipient of neuroleptics (dopamine antagonists) was associated with more impaired basic ADL and instrumental ADL functioning and with more depression symptoms. Several have indicated that dysgraphia is related to severity of AD disorder [56-58]. Hughes et al. [36] have demonstrated the relationships between extent of MMSE 
impairment and patterns of dysgraphia in AD. MMSE deficits in $\mathrm{AD}$ are linked to several co-morbidity domains, including cardiovascular, ear, nose and throat, genitourinary, musculoskeletal/integument and neurologic, as well as severity of impairment of ADL and Cumulative Illness Rating Scale for Geriatrics [59]. Expressions of dysgraphia ought to be considered against this background. Finally, it has been observed that both ADL and IADL fail to reflect caregivers' burden and patients' behavioral symptoms, including affective domains, which need to be assessed in conjunction with cognitive analyses [60].

In conclusion, marked relationships between dysgraphia and several measures of cognitive performance in $\mathrm{AD}$ patients were observed concomitant with consistent deficits by this sample in comparison with a matched group of healthy control subjects. Several measures of loss of functional integrity, MMSE, ADL and IADL, were found to be associated with both dysgraphia and impairments in cognitive performance. These findings imply that assessment of dysgraphia ought to contribute an additional diagnostic assessment that provides evidence of compromised functioning in motor, cognitive and emotional domains [61]. The loss of functional integrity in these AD patients was serious; nevertheless, the manifest benefits arising from a motor interventional set-up, e.g. physical exercise programs, for these patients ought not to be rejected outright [47].

\section{CONFLICT OF INTEREST}

The authors confirm that this article content has no conflict of interest.

\section{ACKNOWLEDGEMENTS}

Special thanks are due to the patients who participated and the UVA structures.

Sources of funding. UVA and University of Gothenburg, Erasmus Foundation.

\section{REFERENCES}

[1] World Health Organization Report. Dementia: a public health priority. Alzheimer Disease International. In: Saxena S, Wortmann M, Eds. WHO Library 2012.

[2] Ravaglia G, Forti P, De Ronchi D, et al. Prevalence and severity of dementia among northern Italian centenarians. Neurology 1999; 53: 416-9.

[3] Thomassen R, van Shaick HW, Blansjaar BA. Prevalence of dementia over age 100. Neurology 1998; 50: 283-6.

[4] WHO. Dementia a public health priority. World Health Organization UK 2012.

[5] Fratiglioni L, Laurer LJ, Andersen K, et al. Incidence of dementia and major subtypes in Europe: a collaborative study of populationbased cohorts. Neurology 2000; 54(Suppl 5): S10-S15.

[6] Lobo A, Launer LJ, Fratiglioni L, et al. Prevalence of dementia and major subtypes in Europe: A collaborative study of populationbased cohorts Neurologic Diseases in the Elderly Research Group. Neurology 2000; 54(Suppl 5): S4-S9.

[7] Tijms BM, Möller C, Vrenken H, et al. Single-subject grey matter graphs in Alzheimer's disease. PLoS One 2013; 8(3): e58921.

[8] World Alzheimer's Report. London: Alzheimer's Disease International 2009.

[9] Diagnostic and Statistical Manual of Mental Disorders IV - TR 2000.
[10] Irwin DJ, Trojanowski JQ Grossman M. Cerebrospinal fluid biomarkers for differentiation of frontotemporal lobar degeneration from Alzheimer's disease. Front Aging Neurosci 2013; 5: 6 .

[11] Robbins SL, Cotran RS. Le basi patologiche delle malattie [The Basic Pathological Indispositions]. Elsevier: Italia 2008; pp. 13869.

[12] Lalla R, Donmez G. The role of sirtuins in Alzheimer's disease. Front Aging Neurosci 2013; 5: 16.

[13] Carbone G, Barreca F, Mancini G, et al. A home assistance model for dementia: outcome in patients with mild-to-moderate Alzheimer's disease after three months. Ann Ist Super Sanita 2013; 49(1): $34-41$

[14] Ricci S, Fuso A, Ippoliti F, Businaro R. Stress-induced cytokines and neuronal dysfunction in Alzheimer's disease. J Alzheimer's Dis 2012; 28(1): 11-24

[15] Ridgway GR, Lehmann M, Barnes J, et al. Early-onset Alzheimer disease clinical variants: multivariate analyses of cortical thickness. Neurology 2012; 79(1): 80-4.

[16] Alzheimer A. Uber eine eigenartige Erkrankung der Hirnrinde [Regarding a strangediseaseofthecortex]. Allgemeine Zeitschrift für Psychiatrisch und Psychischgerichtlich Medizin 1907; 64: 146-8.

[17] Ellis AW. Spelling and writing (and reading and speaking). In: Ellis AW, Ed. Normality and pathology in cognitive functions. London: Academic Press 1982; pp. 113-46.

[18] Roeltgen DP. Agraphia. In: Heilman-Valenstein, Ed. Clinica Neuropsychology. New York: University Press 2003; pp. 126-45

[19] Croisile B. Writing, aging and Alzheimer's disease. Psychol Neuropsychiatr Vieil 2005; 3(3): 183-97.

[20] McNeil MR, Tseng CH. Acquired neurogenic dysgraphias. In: Thieme N, Ed. Aphasia and related neurogenic language disorders. New York: La Pointe Medical Publishers 1990; pp. 147-76.

[21] Lambert J, Giffard B, Nore F, de la Sayette V, Pasquier F, Eustache F. Central and peripheral agraphia in Alzheimer's disease: from the case of Auguste D. to a cognitive neuropsychology approach. Cortex 2007; 43(7): 935-51

[22] Croisile B, Brabant MJ, Carmoi T, Lepage Y, Aimard G, Trillet M. Comparison between oral and written spelling in Alzheimer's disease. Brain Lang 1996; 54: 361-87.

[23] Kumar V, Giacobini E. Use of agraphia in subtyping of Alzheimer's disease. Arch Gerontol Geriatr 1990; 11: 155-9.

[24] Kemper S, LaBarge E, Ferraro FR, Cheung H, Cheung H, Storandt M. On the preservation of syntax in Alzheimer's disease. Arch Neurol 1993; 50: 81-6

[25] Horner J, Heyman A, Dawson D, Rogers H. The relationship of agraphia to the severity of dementia in Alzheimer's disease. Arch Neurol 1988; 45: 760-63.

[26] LaBarge E, Smith DS, Dick L, Storandt M. Agraphia in dementia of the Alzheimer type. Arch Neurol 1996; 49: 1151-6.

[27] Henderson VW, Buckwalter JG, Sobel E, Freed DM, Diz MM. The agraphia of Alzheimer's disease. Neurology 1992; 42: 776-84.

[28] Croisile B, Carmoi T, Adeleine P, Trillet M. Spelling in Alzheimer's disease. Behav Neurol 1995; 8: 135-43.

[29] Neils J, Boller F, Gerdeman B, Cole M. Descriptive writing abilities in Alzheimer's disease. Clin Exp Neuropsychol 1989; 11: 692-8.

[30] Fukui T, Lee E. Progressive agraphia can be a harbinger of degenerative dementia. Brain Lang 2008; 104(3): 201-10.

[31] Neils-Strunjas J, Groves-Wright K, Mashima P, Harnish S Dysgraphia in Alzheimer's disease: a review for clinical and research purposes. J Speech Lang Hearing Res 2006; 49(6): 131330 .

[32] McKhann G, Drachman D, Folstein M, Katzman R, Price D, Stadlan EM. Clinical diagnosis of Alzheimer's disease: report of the NINCDS-ADRDA Work Group under the auspices of Department of Health and Human Services Task Force on Alzheimer's Disease. Neurology 1984; 34(7): 939-44.

[33] Folstein MF, Folstein SE, McHugh PR. Mini-mental state. A practical method for grading the cognitive state of patients for the clinician. J Psychiat Res 1975; 12(3): 189-98.

[34] Krapp K, Ed. Activities of Daily Living Evaluation. Encyclopedia of Nursing \& Allied Health. Gale Group, Inc: USA 2002.

[35] Roley SS, DeLany JV, Barrows CJ, et al. Occupational therapy practice framework: domain and practice. Am J Occup Ther 2008; 62(6): 625-83.

[36] Hughes JC, Graham N, Patterson K, Hodges J. Dysgraphia in mild dementia of Alzheimer's type. Neuropsychologia 1997; 4: 533-45. 
[37] Small JA, Sandhu N. Episodic and semantic memory influences on picture naming in Alzheimer's disease. Brain Lang 2008; 104: 1-9.

[38] Yasuda K, Nakamura T, Beckman B. Brain processing of proper names. Aphasiology 2000; 14: 1067-89.

[39] Silveri MC, Corda F, Di Nardo M. Central and peripheral aspects of writing disorders in Alzheimer's disease. J Clin Exp Neuropsychol 2013 DOI: 10.1080/13803390600611351.

[40] Yoon JH, Suh MK, Jeong Y, et al. Agraphia in Korean patients with early onset Alzheimer's disease. Int Psychogeriatr 2011;23: $1317-26$.

[41] Yoon JH, Kim HH, Seo SW, et al. Dysgraphia in Korean patients with Alzheimer's disease as a manifestation of bilateral hemispheric dysfunction. J Neurol Sci 2012; 320(1-2): 72-8.

[42] Alexander MP, Friedman RB, Loverso F, Fisher RS. Lesion location of phonological dysgraphia. Brain Lang 1992; 43: 83-95.

[43] Hayashi A, Nomura H, Mochizuki R, et al. Neural substrates for writing impairments in Japanese patients with mild Alzheimer's disease: a SPECT study. Neuropsychologia 2011; 49: 1962-8.

[44] Sakurai Y, Mimura I, Mannen T. Agraphia for Kanji resulting from a left posterior middle temporal gyrus lesion. Behav Neurol 2008; 19: 93-106.

[45] Sakurai Y, Onuma Y, Nakazawa G, et al. Parietal dysgraphia: characterization of abnormal writing stroke sequences, character formation and character recall. Behav Neurol 2007; 18: 99-114.

[46] Yaguchi H, Yaguchim M, Bando M. A case of pure agraphia due to left parietal lobe infarction. Brain Nerve 2006; 58: 885-92.

[47] Archer T. Physical exercise alleviates debilities of normal aging and Alzheimer's disease. Acta Neurol Scand 2011; 123: 221-38.

[48] Archer T, Kostrzewa RM. Staging neurological disorders: expressions of cognitive and motor disorder. Neurotox Res 2010; 18(2): 107-11.

[49] Bonnì S, Lupo F, Lo Gerfo E, et al. Altered parietal-motor connections in Alzheimer's disease patients. J Alzheimer's Disorder 2013; 33(2): 525-33.

[50] Carmen T, Antonino S, Francesca M, et al. Impairment of sensorymotor plasticity in mild Alzheimer's disease. Brain Stimul 2013; 6(1): 62-6.
[51] Tippett WJ, Sergio LE, Black SE. Compromised visually guided motor control in individuals with Alzheimer's disease: can reliable distinctions be observed? J Clin Neurosci 2012; 19(5): 655-60.

[52] Sitek EJ, Narozanska E, Barczak A, et al. Agraphia in patients with front temporal dementia and parkinsonism linked to chromosome 17 with P301L MAPT mutation: dysexecutive, aphasic, apraxic or spatial phenomenon? Neurocase 2014; 20(1): 69-86.

[53] Croisile B, Mollion H. Q-ACP: a questionnaire for evaluating visual and gestural complaints in patients with posterior cortical atrophy. Rev Neurol Paris 2011; 167(6-7): 485-94.

[54] Croisile B, Ska B, Brabant MJ, et al. Comparative study of oral and written production in patients with Alzheimer's disease. Brain Lang 1996; 53: 1-19.

[55] Choi J, Myung W, Chung JW, et al. Association between functional impairment, depression, and extrapyramidal signs in neuroleptic-free patients with Alzheimer disease. J Geriatr Psychiatry Neurol 2013; 26(3): 144-50.

[56] Neils J, Roeltgen DP, Greer A. Spelling and attention in early Alzheimer's disease: evidence for impairment of the graphemic buffer. Brain Lang 1995; 49: 241-62.

[57] Platel H, Lambert J, Eustache F, et al. Characteristics and evolution of writing impairment in Alzheimer's disease. Neuropsychologia 1993; 31: 1147-58.

[58] Rapcsak SZ, Arthur SA, Bliklen DA, Rubens AB. Lexical agraphia in Alzheimer's disease. Arch Neurol 1989; 45: 65-8.

[59] Solomon A, Dobranici L, Kåreholt I, Tudose C, Lazarescu M Comorbidity and the rate of cognitive decline in patients with Alzheimer dementia. Geriat Psychiat 2011; 26: 1244-51.

[60] Schiffczyk C, Romero B, Jonas C, Lahmeyer C, Müller F, Riepe MW. Appraising the need for care in Alzheimer's disease. BMC Psychiatry 2013; 13: 73.

[61] Archer T, Kostrzewa RM, Beninger RJ, Palomo T. Staging neurodegenerative disorders: structural, regional, biomarker, and functional progressions. Neurotox Res 2011; 19(2): 211-34.

(C) Onofri et al.; Licensee Bentham Open.

This is an open access article licensed under the terms of the Creative Commons Attribution Non-Commercial License (http://creativecommons.org/licenses/by-nc/3.0/) which permits unrestricted, non-commercial use, distribution and reproduction in any medium, provided the work is properly cited. 